\title{
Makna Pragmatik Tindak Tutur Direktif Pada Tari Gathutkaca Gandrung
}

\author{
Maryono \\ Institut Seni Indonesia (ISI) Surakarta \\ Jl. Ki Hadjar Dewantara No.19 Kentingan, Jebres, Surakarta 57126
}

\begin{abstract}
This research aims to reveal the meaning of Directive Action and Speech of Gatutkaca Gandrung Dance in the custom of Javaness marriage ceremony. This research employs descriptive qualitative using pragmatics theory perspective of Parker and Charles Morris about signs relation. As for the result of the research indicates the domination of directive action and speech in Gatutkaca Gandung dancing performance in the mariage ceremony of javaness culture custom, are interpreted as form of indirect instructions. Penanggap (the parents) desires that the married couple pleases to enjoy the esthetics values, thus the attitude, behavior, and their actions become appropiate. The other directive meaning is so the married couple can grasp the educational values about hard working, enthusiasm, and the heavy struggle that is reflected in Gatutkaca Gandrung Dance to be imitated as provision to establish a harmonious and happy family.
\end{abstract}

Keywords: Dancing, Gatutkaca gandrung, Javaness Custom Marriage Ceremony, Directive Action and Speech.

\begin{abstract}
ABSTRAK
Penelitian ini adalah untuk mengungkap makna pragmatik tindak tutur direktif pada Tari Gathutkaca Gandrung dalam resepsi perkawinan adat Jawa. Penelitian ini menggunakan metode kualitatif deskriptif dengan perspektif teori pragmatik Parker dan Charles Morris tentang relasi tanda. Adapun hasil penelitian ini menggambarkan dominasi tindak tutur direktif dalam pertunjukan Tari Gathutkaca Gandrung pada resepsi perkawinan adat budaya Jawa yang dimaknai sebagai bentuk perintah bersifat tidak langsung. Penanggap (orang tua) menghendaki agar sepasang pengantin berkenan menikmati nilai estetis, supaya jiwanya menjadi lebih halus, lebih santun, peka terhadap lingkungan sehingga sikap, perilaku, dan tindakannya menjadi lebih baik. Makna perintah berikutnya agar sepasang pengantin dapat menyerap nilai-nilai pendidikan tentang usaha yang keras, semangat, dan perjuangan yang berat seperti yang digambarkan pada Tari Gathutkaca Gandrung agar dicontoh sebagai bekal untuk membina keluarga yang harmonis dan bahagia.
\end{abstract}

Kata kunci: Tarian, Gathutkaca Gandrung, resepsi perkawinan adat Jawa, tindak tutur direktif. 


\section{PENDAHULUAN}

Dalam perkembangannya bahasa formal atau struktural yang mengkaji makna berdasarkan internal kebahasaan, tidak lagi mampu untuk mewadahi dan menjawab hakikat makna bahasa dalam realita kehidupan. Dasar pemahamannya bahwa manusia sering berbicara itu tidak selalu bald on record, namun dapat bersifat off record, bahkan ada pula yang sekedar untuk memenuhi phatic communion belaka. Untuk itu muncul bahasa pragmatik sebagai sub disiplin linguistik baru yang mampu menggali hakikat makna bahasa secara kontekstual. Fakta menunjukkan bahwa bahasa merupakan alat komunikasi yang efektif dan efisien dalam kehidupan budaya manusia.

Merujuk pada pernyataan "Pragmatics is the study of how language is used to communicate" (Parker, 1986:11), bahwa satuan-satuan kebahasaan dalam kerangka pragmatik itu mengkaji makna pada perspektif aktif melakukan tugas atau yang difungsikan sebagai sarana komu-nikasi, bukannya satuan-satuan kebahasa-an pada posisi pasif. Hal itu diperkuat oleh Asim Gunarwan yang menyatakan bahwa pragmatik berkaitan dengan penggunaan bahasa, yaitu bagaimana bahasa digunakan oleh penutur di dalam situasi interaksi yang sebenarnya, bukan di dalam situasi yang diabstraksikan, yang direka-reka oleh linguis (Asim Gunarwan, 2005: 1). Untuk menemukan makna dalam khasanah pragmatik dengan cara menganalisis satuansatuan kebahasaan secara eksternal. Pada tataran yang demikian semakin jelas bahwa makna yang dikaji pada pragmatik merupakan contextual dependent.

Berkomunikasi dengan bahasa dapat dilakukan dengan menggunakan cara verbal, nonverbal, maupun campuran dari kedua komponen tersebut. Menurut
Lamuddin berkomunikasi dengan cara verbal dilakukan dengan bahasa tertulis ataupun lisan, sedangkan komunikasi dengan cara nonverbal dilakukan dengan memakai media selain bahasa yang wujudnya dapat berupa aneka simbol, isyarat, kode dan bunyi-bunyian (Lamuddin, 2005: 2). Dalam komunikasi bahasa pragmatik seni pertunjukan, rupanya yang digunakan adalah cara campuran, yaitu perpaduan komponen yang bersifat verbal dan nonverbal. Mengingat salah satu bahasa pragmatik yang hidup subur di masyarakat adalah di antaranya berupa seni pertunjukan, baik berupa tari, ketoprak, wayang, langendriyan, dan sebagainya.

Seni pertunjukan pada dasarnya merupakan bahasa komunikasi yang bersifat pragmatik dari seniman terhadap penonton. Tari Gathutkaca Gandrung sebagai salah satu genre seni pertunjukan memiliki komponen verbal dan nonverbal yang berkualitas. Komponen verbal Tari Gathutkaca Gandrung, berupa sastra tembang dalam bentuk garap: ada-ada, sendhon, dan gerongan. "Adapun komponen nonverbal, berupa tema, gerak, busana, rias, dan musik. Kedua komponen baik yang bersifat verbal maupun nonverbal merupakan suatu tanda yang sengaja diberi makna oleh seniman sehingga menjadi lambang yang memiliki arti bagi penonton. Pada presentasinya kedua komponen tersebut disajikan dalam bentuk seni pertunjukan yang padu, utuh, harmoni, berkualitas, dan bermakna. Pada prinsip dasarnya pragmatik adalah subdisiplin linguistik yang mengaitkan bahasa sebagai sistem lambang dengan pengguna atau user bahasa (Mey, 1998:716737). Untuk itu sangat tepat bahwa Tari Gathutkaca Gandrung merupakan salah satu sasaran kajian pragmatik.

Landasan teori yang digunakan mengkaji makna Tari Gathutkaca Gandrung, 
adalah teori pragmatik dan teori seni pertunjukan. Pembagian wilayah analisisnya, teori-teori pragmatik yang berkait dengan jenis-jenis tindak tutur, konteks, implikatur atau makna dibalik yang tersurat pada komponen yang bersifat verbal kebahasaan. Teori seni pertunjukan secara fokus untuk mengungkap makna dibalik wujud simbol-simbol yang bersifat nonverbal. Hasil dari analisis kedua komponen tersebut merupakan temuan yang diakselerasikan menjadi sebuah simpulan akhir.

\section{METODE}

Metode penelitian kualitatif merupakan pilihan yang tepat untuk mengungkap makna Tari Gathutkaca Gandrung. Langkah-langkah yang ditempuh untuk mendapatkan data dari berbagai sumber, peneliti menggunakan beberapa metode, yaitu: studi pustaka, observasi, dan wawancara. Studi pustaka dilakukan untuk memperoleh informasi yang berkait dengan cerita, tema, dan sumber tertulis yang dimanfaatkan sebagai referensi maupun rujukan teoritis. Observasi lebih bersifat langsung dan tidak langsung untuk mendapatkan data-data komponen yang bersifat verbal dan nonverbal. Bentuk wawancara lebih bersifat terbuka dan cenderung tidak formal untuk memperoleh data-data yang berkaitan dengan objektif, genetik, dan afektif.

\section{HASIL DAN PEMBAHASAN}

\section{Bentuk Tari Gathutkaca Gandrung}

Tari Gathutkaca Gandrung merupakan salah satu bentuk tari gagah gaya Surakarta yang disajikan secara tunggal dengan mengangkat tema percintaan atau gandrungan. Sekitar tahun 1983, S. Maridi menawarkan susunan karya Tari Gathutkaca Gandrung yang didokumentasikan oleh PN
Lokananta. Rupanya setelah sukses menghantarkan karya-karyanya seperti Tari Eko Prawiro (1961), Tari Prawirowatang (1962), Tari Karonsih (1970), Tari Endah (1971), Dramatari Wandansari (1980), dan Dramatari Panji Semirang (1981) S. Maridi semakin mendapat kepercayaan dari masyarakat dan PN Lokananta untuk memublikasikan karyanya lewat rekaman gendhing-gendhing beksan (lihat S. Pamardi, 2000: 83-84). Semangat dan motivasi S. Maridi yang demikian sesuai dengan pernyataan Myron Weiner (1986:2), bahwa faktor yang mendorong suatu negara untuk dapat berkembang pesat adalah virus mental, yaitu suatu cara berpikir tertentu yang apabila terjadi pada diri seseorang, cenderung menyebabkan orang tersebut menjadi tumbuh bersemangat untuk berbuat, bertingkah laku memenuhi kebutuhan prestasinya (Weiner, 1986: 2).

Kehadiran Tari Gathutkaca Gandrung susunan S. Maridi lebih banyak menjadi sajian pada acara-acara resepsi perkawinan masyarakat bernuansa budaya Jawa. Rupanya terdapat keselarasan dan kecocokan antara tema tari Gandrungan atau percintaan dengan peristiwa percintaan yang dialami oleh sepasang pengantin, menjadikan banyak masyarakat terpikat pada pertunjukan Tari Gathutkaca Gandrung (Sutarno Haryono, wawancara: 2014). Bagi masyarakat Jawa pada umumnya, simbolisme memiliki peranan penting dalam memenuhi kebutuhan kehidupan berbudaya. Upacara perkawinan bagi masyarakat Jawa dianggap sebuah peristiwa yang sakral, di mana di dalamnya terkandung unsur-unsur crisis-rites sehingga segala sesuatu yang berkaitan dengan syaratsyarat upacara diadakan. Hal itu diyakini oleh masyarakat untuk memperoleh keselamatan dan kebahagiaan (Koentjaraningrat, 1972: 89-94). 
Tabel. 1: Jenis - jenis Tindak Tutur (TT)

\begin{tabular}{|c|c|c|c|c|}
\hline No & Penutur & $\begin{array}{c}\text { Teks Verbal Ada-ada Greget Saut laras } \\
\text { slendro pathet sanga }\end{array}$ & $\begin{array}{l}\text { Jenis- } \\
\text { ienis } \\
\text { TT }\end{array}$ & Pemarkah \\
\hline 1.1 & Yokalis putra & Irikata sang Gathutkaca kinen. & Direktif & kinon \\
\hline 1.2 & Vokalis putra & Mapak Arka suta $O \ldots$ & Direktif & mapak \\
\hline 1.3 & Vokalis putra & Tekapira Kresna & Direktif & tekan ira. \\
\hline 1.4 & Vokalis putra & Darta maneher muja saktinira. & Direktif & muja saktinira \\
\hline 1.5 & Vokalis putra & $\begin{array}{l}\text { Sang inujaran wang-wang semu hanggariita, } \\
\text { O... }\end{array}$ & Direktif & sang inujaran \\
\hline
\end{tabular}

Keterangan: Jenis-jenis Tindak Tutur yang melekat pada Teks Ada-ada Greget Saut laras slendro pathet sanga dan Pemarkah.

\section{Bentuk Komponen verbal}

Dasar pemahaman yang perlu dicermati tentang komponen verbal yang terdapat dalam Tari Gathutkaca Gandrung adalah jenis-jenis kebahasaan yang secara substantif digunakan untuk komunikasi. Bentuk komunikasi dalam pertunjukan Tari Gathutkaca Gandrung dapat bersifat langsung dan tidak langsung. Adapun jenisjenis komponen verbal secara keseluruhan yang terdapat pada Tari Gathutkaca Gandrung, yaitu: (1) Teks Ada-ada Greget Saut laras slendro pathet sanga, (2) Teks Sendhon Tlutur laras slendro pathet sanga, (3) Teks Ketawang Kinanthi Pawukir laras slendro pathet sanga, dan (4) Teks Ada-ada Greget Saut laras slendro pathet manyura. Ragam komponen verbal yang difungsikan secara langsung oleh penari sebagai media komunikasi terdiri dari teks Ketawang Kinanthi Pawukir laras slendro pathet sanga. Aktualisasinya teks Ketawang Kinanthi Pawukir laras slendro pathet sanga dinyanyikan penari Raden Gathutkaca untuk merayu kekasihnya, yaitu Dewi Pergiwa.

Beberapa jenis teks yang pemanfaatannya bersifat tidak langsung tersebut, lebih banyak digunakan sebagai bentuk ilustrasi penggambaran kondisi atau fakta suasana yang tengah dialami atau menyelimuti kondisi psikologis tokoh yang ditampilkan. Wujud presentasinya jenis-jenis teks yang mencakup: Ada-ada Greget Saut laras slendro pathet sanga, Sendhon Tlutur laras slendro pathet sanga, dan Ada-ada Greget Saut laras slendro pathet manyura dilantunkan oleh seorang vokalis putra (pemusik) sebagai bentuk penggambaran menurut suasana pada masing-masing adegan. Untuk itu bentuk analisis yang tepat lebih fokus pada masing-masing teks verbal secara parsial kemudian menyeluruh dengan teori pragmatik yang berkenaan dengan klasifikasi tindak tutur, konteks yang melingkupinya, dan implikatur-implikatur yang mengarah pada pemaknaan utama dari komponen verbal pada Tari Gathutkaca Gandrung. Menurut George Yule, jenis-jenis tindak tutur yang terdapat dalam sebuah komunikasi setidaknya dapat diklasifikasikan menjadi lima macam, yaitu: deklaratif, representatif, ekspresif, direktif, dan komisif (Yule, 2006: 92-94). Berdasarkan teori tindak tutur yang dinyatakan Yule, jenis-jenis komponen verbal Tari Gathutkaca Gandrung akan dikaji secara menyeluruh.

\footnotetext{
Teks Ada-ada Greget Saut laras slendro pathet sanga Irikata sang Gathutkaca kinon, Mapak Arka suta, O........ Tekap ira Kresna,
} 
Parta maneher muja saktinira,

Sang inujaran wang-wang semu hanggarjita, O.........

[Diceriterakan, ketika Sang Gathutkaca disuruh, Untuk melawan Sang Basukarno, Atas kehendak Sri Kresna, Raden Harjuna juga mendukung dan memberi penguatan terhadap Sang Gathutkaca, Jiwa Sang Gathutkaca semakin berani dan percaya atas perintah Sri Kresna untuk melawan musuh] (Suyanto, 2014: wawancara).

\section{Konteks}

Arti konteks adalah sebuah konsep yang dinamis, bukan statis. Konteks dipahami sebagai sebuah lingkungan yang selalu berubah yang memungkinkan peserta tutur berinteraksi dan membantu mereka memahami ungkapan-ungkapan kebahasaan yang mereka gunakan dalam suatu proses komunikasi (Mey, 2001:39-42). Peserta tutur: vokalis putra (penutur/pn) dan audien (petutur/pt). Tema: peperangan. Tujuan: memberikan semangat terhadap Raden Gathutkaca. Status sosial: Raden Gathutkaca merupakan raja muda dari Kerajaan Pringgondani. Ia merupakan kesatria yang kelak menjadi senopati para Pandawa ketika Perang Baratayuda. Kesaktian Raden Gathutkaca digambarkan bagaikan kerangka baja tubuhnya, bisa terbang tanpa sayap karena memiliki Kotang Antrakusuma, dan tidak pernah kehujanan karena memiliki Payung Basunanda serta mempunyai alas kaki Tlumpah Padakacarma yang bisa berjalan dalam kondisi apapun. Ketiga ajian yang dimiliki Raden Gathutkaca yang berupa: Kotang Antrakusuma, Payung Basunanda, dan Tlumpah Padakacarma merupakan kesaktian yang telah menyatu dengan jiwanya sehingga tidak selalu ditampakkan dalam wujud visual, kecuali Kotang Antrakusuma. Tempat: pertuturan terjadi di kerajaan. Situasi tutur: situasi formal.

Levinson berpendapat implikatur percakapan adalah "the notion of conversational implicature is one of the single most important ideas in pragmatics" (1983: 97). Secara ringkas implikatur dapat dinyatakan sebagai sebuah makna yang disiratkan dalam percakapan. Adapun implikatur Ada-ada Greget Saut laras slendro pathet sanga adalah bentuk ungkapan semangat, motivasi, dan dukungan terhadap jiwa Raden Gathutkaca dalam menggapai cintanya.

Teks Sendhon Tlutur laras slendro pathet sanga

O ......Surem-surem diwangkoro kingkin, Lir manguswa kang layon,

Tabel. 2: Jenis-jenis Tindak Tutur (TT)

\begin{tabular}{|c|c|c|c|}
\hline Penutur (Pn) & $\begin{array}{c}\text { Teks Sendhon Tlutur laras slendro } \\
\text { pathet sansa }\end{array}$ & $\begin{array}{l}\text { Jenis-ienis } \\
\text { TT }\end{array}$ & Pemarkah \\
\hline Vokalis putra & $\begin{array}{l}\text { O...Surem-surem diwangkoro } \\
\text { kingkin, }\end{array}$ & Representatif & surem-surem diwangkoro \\
\hline Vokalis putra & Lir manguswa kang layon, & Representatif & lir mansuszwa \\
\hline Vokalis putra & O...Dènya ilang ingkang memanisé, & Ekspresif & dènyailang memanisé \\
\hline Vokalis putra & Wadananira layu, & Ekspresif & wadananira lauu \\
\hline Vokalis putra & Kumel kucem rahnya maratani, $O \ldots$ & Ekspresif & kumel kucem. \\
\hline
\end{tabular}

Keterangan: Jenis-jenis Tindak Tutur yang melekat pada Teks Sendhon Tlutur laras slendro pathet sanga dan Pemarkah. 
Tabel. 3: Jenis-jenis Tindak Tutur (TT)

\begin{tabular}{llcc}
\hline Penutur (Pn) & $\begin{array}{c}\text { Teks Ketawnang Kinanthi Pawukir laras } \\
\text { slendro pathet sanga }\end{array}$ & Ienis-ienis TT & Pemarkah \\
\hline Gathutkaca & Mbalung Pakèl domba gunung, & Direktif & mbalung pakèl \\
Gathutkaca & Téja béngkok noinum warih, & Direktif & noinum waarih \\
Gathutkaca & Sun luwung akrama kadang, & Komisif & sun luwung \\
Gathutkaca & Dadi lok ing wong sabumi, & Direktif & dadi loking \\
Gathutkaca & Rejaso kang pindha warna, & Representatif & kang pindha \\
Gathutkaca & Sun temah dadiya krami. & Direktif & dadiua \\
\hline
\end{tabular}

Keterangan: Jenis-jenis Tindak Tutur yang melekat pada Teks Ketawang Kinanthi Pawukir laras slendro pathet

\section{O ......Dènya ilang ingkang memanisé,}

Wadananira layu,

Kumel kucem rahnya maratani, O.....

[Matahari tampak suram, Bagaikan mengabarkan mayat, Yang tengah hilang pamor atau sinarnya, Wajahnya pucat, Jelek, sedih darahnya membeku melumuri seluruh tubuh] (Suyanto, 2014: wawancara,).

\section{Konteks}

Peserta tutur: vokalis putra (penutur) dan audien (petutur). Tema: kesedihan Raden Gathutkaca. Tujuan: menggambarkan Raden Gathutkaca ketika jatuh kantaka dari terbang, ketika hendak menemui Dewi Pergiwa. Status sosial: Raden Gathutkaca merupakan raja muda dari Kerajaan Pringgondani. Ia merupakan kesatria yang kelak menjadi Senopati Pandawa ketika Perang Baratayuda. Kesaktian Raden Gathutkaca digambarkan bagaikan kerangka baja tubuhnya, bisa terbang tanpa sayap karena memiliki Kotang Antrakusuma, dan tidak pernah kehujanan karena memiliki payung Basu-nanda serta mempunyai alas kaki tlumpah padakacarma yang bisa berjalan dalam kondisi apapun. Tempat: pertuturan terjadi di luar kerajaan. Situasi tutur: situasi tidak formal.
Implikatur adegan beksan bagian sedih adalah bentuk kesedihan yang mendalam yang dialami Raden Gathutkaca, ketika ia dimabuk cinta oleh pujaan hatinya sehingga tidak mampu mengontrol dan jatuh, lemah tak berdaya bagaikan mayat. Kondisi tubuh Raden Gathutkaca digambarkan seolah-olah tidak memiliki roh, wajahnya pucat, dan seluruh darahnya membeku membuat seluruh jiwanya tidak bergairah.

Teks Ketawang Kinanthi Pawukir laras slendro
pathet sanga
Mbalung pakèl domba gunung,
Téja béngkok nginum warih,
Sun luwung akrama kadang,
Dadi lok ing wong sabumi,
Reja sokang pindha warna,
Sun temah dadiya krami.

[Kelihatan jelas bagaikan seekor kijang, Pelangi melengkung bagaikan minum warih,Saya lebih baik kawin dengan saudara, Meskipun menjadi pergunjingan orang banyak, Dalam kondisi bagaimanapun, Saya sengaja, ia tetap menjadi istriku] (Suyanto, 2014: wawancara).

\section{Konteks}

Peserta tutur: Raden Gathutkaca (penutur) dan audien (petutur). Tema: kasmaran atau gandrungan. Tujuan: menggambarkan 
Raden Gathutkaca ketika sedang merayu Dewi Pergiwa. Status sosial: Raden Gathutkaca merupakan raja muda dari Kerajaan Pringgondani. Ia merupakan kesatria yang kelak menjadi Senopati Pandawa ketika Perang Baratayuda. Situasi tutur: situasi tidak formal.

Implikatur adegan beksan bagian kasmaran adalah merepresentasikan tentang lamunan rayuan Raden Gathutkaca yang menghendaki agar Dewi Pergiwa tetap menjadi istrinya. Ketetapan atinta telah bulat meskipun ia sadar bahwa Dewi Pergiwa masih adik keponakan sehingga masalah pergunjingan akan muncul setiap saat. Untuk itu niat dan kehendaknya telah kukuh dinyatakan dalam tuturan Ketawang Kinanthi Pawukir baris ke-3 dan ke-4 yang berbunyi: “Sun luwung akrama kadang, Dadi lok ing wong sabumi. Kemudian dipertegas lagi pada tindak tutur ke-6, yang berbunyi: "Sun temah dadiya krami".

Teks Ada-ada Greget Saut laras slendro pathet manyura

Tandya krodha sang Gathutkaca,

Wang-wang murca mangesak samya, $O$...

Dèn tan jrih mabangun.

Sawéga tumempuh mangungsir wong gati,

Singgih Bima suta.

[Sang Gathutkaca marah, Hilanglah segala keraguan, Tidak ada rasa takut untuk bangkit, Siap siaga untuk melawan, mendesak musuh, Itulah tekad Gathutkaca putra Bima] (Suyanto, 2014: wawancara).

\section{Konteks}

Peserta tutur: vokalis putra (penutur) dan audien (petutur). Tema: semangat. Tujuan: menggambarkan semangat Raden Gathutkaca untuk segera bertemu dan kawin dengan Dewi Pergiwa. Status sosial: Raden Gathutkaca merupakan raja muda dari kerajaan Pringgondani. Ia merupakan kesatria yang kelak menjadi Senopati
Pandawa ketika Perang Baratayuda. Situasi tutur: situasi tidak formal.

Implikatur Adegan Mundur Beksan adalah menggambarkan rasa semangat Raden Gathutkaca untuk mewujudkan cintanya terhadap kekasihnya Dewi Pergiwa. Kesadarannya dari lamunan, bayangan cinta, dan mabuk asmaranya dengan Dewi Pergiwa pujaan hatinya, membuatnya terbangun dan bangkit untuk segera mengungkapkan kehendak rasa cinta dan mewujudkannya dalam perkawinan. Rasa cinta dari lubuk hati yang paling dalam pada dirinya, rupanya mampu memberikan spirit dan motivasi yang kuat sehingga menghantarkan pada tekadnya yang tidak pernah ragu, bimbang, takut terhadap segala rintangan yang siap menghambat sekalipun.

\section{Bentuk Komponen Nonverbal}

Tari Gathutkaca Gandrung merupakan ekspresi seniman yang menggunakan media bahasa yang bersifat nonverbal. Seperti ditegaskan Lamuddin Finoza, bahwa dalam berkomunikasi selain menggunakan bahasa verbal, dapat pula dilakukan dengan cara-cara nonverbal yang wujudnya dapat berupa aneka simbol, isyarat, kode, dan bunyi-bunyian (Lamuddin, 2005: 2). Adapun wujud komponen nonverbal pada Tari Gathutkaca Gandrung, berupa: tema, gerak, busana, rias, dan musik. Komponen nonverbal pada Tari Gathutkaca Gandrung pada dasarnya merupakan media ungkap yang mengandung sensasi. Sekalipun sensasi itu selalu ada dan nilainya sangat mutlak dalam seni atau keindahan, namun tidak semua jenis sensasi sesuai masuk dalam pengalaman seni (Parker, 1980: 79).

Komponen nonverbal pada Tari Gathutkaca Gandrung sebagai bentuk sensasi yang sengaja dicipta dengan cita 
Tabel. 4: Jenis-jenis Tindak Tutur (TT)

\begin{tabular}{|c|c|c|c|}
\hline Penutur (Pn) & $\begin{array}{c}\text { Teks Ada-ada Greget Saut laras slendro } \\
\text { pathet manuura }\end{array}$ & $\begin{array}{l}\text { Jenis-jenis } \\
\text { TT }\end{array}$ & Pemarkah \\
\hline Vokalis putra & Tandya krodha sang Gathutkaca, & Direktif & $\operatorname{tandya}$ \\
\hline Vokalis putra & Wang-wang murca mangesak samya, $O \ldots$ & Direktif & murca \\
\hline Vokalis putra & Dèn tan jrih mabangun, & Direktif & dèn tan irih \\
\hline Vokalis putra & Sawéga tumempuh mangungsir wong gati, & Direktif & sawéga tumempuh \\
\hline Vokalis putra & Singgih Bima suta. & Representatif & singoih \\
\hline
\end{tabular}

Keterangan: yang melekat pada Teks Ada-ada Greget Saut laras slendro pathet manyura dan Pemarkah.

rasa keindahan seniman tari supaya memiliki kekuatan pacu dan nilai keindahan sehingga mampu memikat dan menggerakkan jiwa para penghayatnya. Hal itu sejalan dengan pernyataan bahwa nilai estetis adalah sifat (kualitas) yang memang telah melekat pada benda yang indah, terlepas dari orang yang mengamatinya. Pengamat hanya tinggal menyingkap atau menemukan sifat-sifat keindahan yang sudah melekat pada bendanya dan sama sekali tidak berpengaruh untuk mengubahnya (Liang Gie, 1976: 41). Rupanya menjadi tidak berlebihan bila sarana-sarana ungkap nonverbal yang bersifat simbolik pada Tari Gathutkaca Gandrung, memiliki peranan yang sangat penting dalam aktualisasinya. Ditekankan oleh Dewitt. H Parker bahwa hampir semua karya seni itu mengandung unsur-unsur sensa yang tidak hanya pada dirinya melainkan terdapat fungsi untuk melambangi benda, peristiwa, atau universal (Parker, 1980: 77).

\section{Tema}

Cerita Tari Gathutkaca Gandrung pada dasarnya bertemakan tentang percintaan atau Gandrungan. Tari ini menggambarkan percintaan kesatria dari Pringgandani yaitu Raden Gathutkaca terhadap Dewi Pergiwa dari Ngandong Sumawi. Dalam kisahnya
Raden Gathutkaca adalah putra dari perkawinan Dewi Arimbi dan Raden Werkudara yang merupakan putra kedua Raden Pandhu dan Dewi Kunthi. Adapun Dewi Pergiwa adalah putri Dewi Manohara dan Raden Harjuna yang juga masih paman Raden Gathutkaca (Suyanto, 2014: wawancara). Perjalanan cintanya untuk mendapatkan Dewi Pergiwa harus dilalui dengan suatu peperangan yang cukup berat dengan para Kurawa yang hendak meminangnya untuk putra Raja Hastina, yaitu Lesmana Madrakumara.

Pada awalnya percintaan Raden Gathutkaca pada Dewi Pergiwa tidak mendapat restu dari Raden Harjuna sebagai orang tua Pergiwa. Ketika itu Raden Harjuna sudah dipengaruhi oleh para Kurawa, ia lebih memilih putrinya untuk dikawinkan dengan Lesmana Madrakumara. Upaya yang dilakukan Raden Gathutkaca adalah mengajak pergi Dewi Pergiwa; di tengah perjalanan mereka dihadang Raden Harjuna, terjadilah peperangan dan Raden Gathutkaca kalah. Sebagai orang tua melihat anaknya dihajar oleh adiknya, Raden Werkudara marah dan Raden Harjuna kemudian dihajar. Pada saat perkelahian semakin keras datang Sri Kresna melerai dan mendamaikan kakak beradik tersebut. Raden Gathutkaca dengan 
Tabel 5: Rekapitulasi jenis-jenis TT pada komponen verbal Tari Gathutkaca Gandrung.

\begin{tabular}{|c|c|c|c|c|c|c|}
\hline No & Jenis TT & $\begin{array}{l}\text { Teks Ada-ada } \\
\text { Greget Saut laras } \\
\text { slend ro pathett } \\
\text { sanga }\end{array}$ & $\begin{array}{c}\text { Teks Sendhon } \\
\text { Tlutur laras } \\
\text { stendre pathet } \\
\text { sanga }\end{array}$ & $\begin{array}{l}\text { Teks Ketawans } \\
\text { Kinanthi } \\
\text { Dawukkir laras } \\
\text { slendro pathet } \\
\text { sanga }\end{array}$ & $\begin{array}{c}\text { Teks Ada-ada } \\
\text { Greset Saut } \\
\text { laras Slendro } \\
\text { pathet } \\
\text { manuura }\end{array}$ & Iumlah \\
\hline $\begin{array}{l}1 \\
2 \\
3 \\
4 \\
5 \\
6\end{array}$ & $\begin{array}{l}\text { Deklarasi } \\
\text { Representatif } \\
\text { Ekspresif } \\
\text { Direktif } \\
\text { Komisif }\end{array}$ & $\begin{array}{ll}- & \\
- & \\
5 & \\
- & \\
& \end{array}$ & $\begin{array}{l}5 \\
2 \\
3 \\
- \\
-\end{array}$ & $\begin{array}{l}- \\
1 \\
\overline{4} \\
1\end{array}$ & $\begin{array}{l}- \\
1 \\
\overline{4} \\
-\end{array}$ & $\begin{array}{c}- \\
4 \\
3 \\
13 \\
1 \\
21\end{array}$ \\
\hline
\end{tabular}

Tabel 6.: Persentase jenis-jenis TT pada komponen verbal Tari Gathutkaca Gandrung.

\begin{tabular}{llcc}
\hline No & \multicolumn{2}{c}{ Jenis-ienis TT pada komponen verbal Tari Gathutkaca } \\
Gandrung & Jumlah \\
\hline 1 & Deklarasi & $4: 21 \times 100$ & - \\
2 & Representatif & $3: 21 \times 100$ & $19.04 \%$ \\
3 & Ekspresit & $13: 21 \times 100$ & $14.30 \%$ \\
4 & Direktif & $1: 21 \times 100$ & $61.90 \%$ \\
5 & Komisif & Jumlah total & $4.76 \%$ \\
6 & & & $100 \%$ \\
\hline
\end{tabular}

sigap menghalau para Kurawa. Akhir cerita Raden Harjuna juga merestui perkawinan Raden Gathutkaca dengan Dewi Pergiwa.

Tari Gathutkaca Gandrung ini merupakan susunan S. Maridi pada sekitar tahun 1983 (Kaset Gendhing Beksan yang berjudul Karonsih). Bentuk tarinya adalah termasuk jenis tari tunggal percintaan atau gandrungan. Pada presentasinya tari ini disajikan secara tunggal; adapun tokoh Dewi Pergiwa sebagai lamunan Raden Gathutkaca. Dalam perkembangannya di tengah-tengah masyarakat tari ini juga pernah disajikan berpasangan antara tokoh Gathutkaca dan tokoh Pergiwa yang dihadirkan sebagai bayangan. Berdasarkan temanya Tari Gathutkaca Gandrung susunan S. Maridi dalam aktualisasinya dapat dijabarkan menjadi tiga bagian utama, yaitu: maju beksan, beksan dan mundur beksan. Masing-masing bagian terdiri dari sub-sub yang di antaranya: maju beksan (ada-ada dan sampak); beksan (sendhon, ketawang Kinanthi Pawukir, ada-ada, lancaran Bendrong, Pucung Rubuh, lancaran Bendrong); mundur beksan (sampak).

\section{Gerak}

Pada kalangan tradisi pola gerak dasar yang diterapkan untuk tari putra gagah terbagi menjadi dua kelompok besar, yaitu pola: Kalang Kinantang Kasatrian dan Kalang Kinantang Punggawan (Nanik Sri Prihatini dkk, 2007: 7-8). Berdasarkan pembagian pola tersebut, Tari Gathutkaca Gandrung merupakan salah satu jenis tari putra gagah dugangan yang menggunakan pola gerak dasar Kalang Kinantang Kasatrian. Dasar pemikiran tentang pola gerak tari tersebut adalah mengacu pada status atau derajat sosial, di mana Raden Gathutkaca merupakan kesatria dari darah Pandawa.

Secara visual tampak tidak dapat terbantahkan bahwa kehadiran gerak merupakan media yang sangat dominan dalam pertunjukan tari. Rupanya tanpa 
kehadiran gerak tidak terwujud sebuah pertunjukan tari untuk itu sebagai media yang utama, gerak harus mampu mengaktualisasikan pesan seniman baik yang tersurat maupun yang tersirat. Untuk itu seniman sebagai sumber pesan yang sekaligus sumber munculnya karya seni, harus kreatif dalam merepresentasikan idealismenya lewat beragam bentuk gerak agar dapat ditangkap dan dinikmati masyarakat penonton sebagai sasarannya. Gerak sebagai bahasa nonverbal dalam perwujudannya dituntut mampu mengungkapkan pesan seniman.

Secara garis besar gerak dalam pertunjukan tari dapat dikategorikan menjadi dua jenis, yaitu gerak yang bersifat presentatif dan gerak yang bersifat representatif. Beragam jenis-jenis gerak presentatif dipahami sebagai bentuk gerak yang tidak memiliki maksud atau arti tertentu, yang difungsikan sematamata untuk ekspresi estetis. Adapun jenisjenis gerak represen-tatif merupakan bentuk gerak yang mere-presentasikan atau menghadirkan kembali dari gerak sesuatu yang terdapat di lingkungan sekitar kita (Maryono, 2010 : 56). Bentuk gerak-gerak representatif pada dasarnya lebih cenderung mengimitasi sehingga perwujudannya lebih tampak dalam penggambaran maupun maksud yang dikehendaki dari seniman penyusunnya. Berdasarkan pada cerita dan tema yang dipilih masing-masing bagian merepresentasikan kondisi dan situasi perjalanan kasmaran Raden Gathutkaca, yang secara struktural geraknya dapat digambarkan sebagai berikut. Untuk penggambaran jenis-jenis gerak yang bersifat representatif akan diberi simbol (r), sedangkan untuk jenis-jenis gerak yang bersifat presentatif akan diberi simbol (p).

\section{Alur gerak maju beksan: adegan pencarian}

Rasa semangat Raden Gathutkaca untuk segera bertemu pujaan hati, yaitu Dewi
Pergiwa tidak dapat dibendung, maka mulai ada persiapan yang cukup matang dengan dukungan gerak laku jèngkèngan (r) menuju panggung, sembahan (r), berdiri sabetan (p). Rasa kasmaran yang bergejolak dihatinya mendorong untuk melesat terbang ke angkasa menuju taman-sari Ndederpenyu yang diekspresikan dengan gerak srisik kanan (r), srisik kiri berputar-putar (r), srisik kanan ke pojok kiri (r), lalu trécétan tangan kiri kebyok sampur tangan kanan menthang miwir sampur (r), mundur memutar dan jatuh kantaka (r) (setengah sadar). Aktualisasi bentuk gerak bagian pencarian dilakukan dengan sigap, tegas dalam irama sedang.

\section{Alur gerak beksan: adegan sedih}

Rupanya sikap kehati-hatian Raden Gathutkaca tidak memadai, tindakan emosional lebih tinggi kurang terkontrol, nafsu asmara semakin membara sehingga terjatuh. Setelah sadar Raden Gathutkaca menangis dengan gerak tangan kiri menutup mata dengan sampur dan tangan kanan usap waspa (r). Kondisi Gathutkaca semakin membaik, emosional tampak terkontrol, ia mulai duduk bersila sambil melipat kedua tangannya (sedhakep) (r) sambil memandang ke arah bawah samping kiri. Sajian seluruh jenis gerak yang terdapat pada adegan sedih tampak lebih berirama pelan dan penuh kehati-hatian.

\section{Alur gerak beksan: adegan kasmaran (1) \\ Pandangan mata mulai menjauh lalu jèngkèngan (r), melihat ke arah kiri dengan ulap-ulap tawing ( $\mathrm{r}$ ) kiri seolah-olah baya- ngan Pergiwa datang dengan sigap ia ber- diri. Bayangan Dewi Pergiwa seolah sema- kin berada di depannya dan didekatinya de-ngan gerak podhongan sampur kiri (r), lalu pindah podhongan sampur kanan (r). Disadarinya hanya sebuah lamunan ia mulai sadar lalu gerak mundur sambil}


melepas kedua sampur, tanjak kiri (r), ulapulap tawing kiri (r), sabetan (p), dan tanjak kanan (r). Pre-sentasi dari jenis-jenis gerak untuk adegan kasmaran, iramanya pelan penuh nuansa romantis.

\section{Alur gerak beksan: adegan semangat (1)}

Semangat Raden Gathutkaca untuk bertemu Dewi Pergiwa mulai tumbuh kembali yang diekspresikan dengan gerak tanjak kiri (r), ulap-ulap tawing kiri (r), ulapulap tawing kanan (r), ukel gelung ( $\mathrm{r}$ ), usap brengos $(\mathrm{r})$, nglurup wangkingan $(\mathrm{r})$ sabetan (p), dan tanjak kanan (r). Rasa semangatnya semakin meningkat dan rasa percaya diri semakin kuat dengan dukungan gerak sabetan ( $\mathrm{p})$, trécétan ke kanan (r), ogékan lambung (r), trécétan ke kiri (r), ogékan lambung (r), lumaksana Kalangtinantang (r), ombak banyu (p), srisik (r), besut (p), dan tanjak kanan (r). Pengungkapan gerak gerak yang terdapat pada bagian ini cenderung berirama sedang dan bernuansa semangat.

\section{Alur gerak beksan: adegan kasmaran (2).}

Pada adegan kasmaran tahap kedua ini Raden Gathutkaca mulai tampak semangat dan mulai gembira, adapun gerak-gerak yang dimanfaatkan untuk menggambarkan suasana tersebut, diantaranya: ogékan lambung gedhegan (r), usap brengos (r), lumaksana Kalangtinantang ( $\mathrm{r}$ ), podhongan sampur kiri (r), mundur lumaksana Kalangtinantang (r), besut (p), ogékan sampir sampur (r), laku telu pondhongan sampur (r), besut (p), laku jajak (r), ombak banyu (p), srisik (r), besut (p), dan tanjak kanan (r). Pada adegan kasmaran tahap kedua ini, beragam gerak yang ditampilkan berirama sedang dan penuh semangat romantis.

\section{Alur gerak beksan: adegan gembira}

Suasana gembira diungkapkan ketika ia merasa sudah semakin berdekatan dengan kekasihnya, yaitu Dewi Pergiwa. Bayangan Dewi Pergiwa dimata Raden Gathutkaca terasa memberikan spirit, perhatian, dan penguatan sehingga ia merasakan tersanjung dengan memperlihatkan maskulinitasnya. Jenis-jenis gerak yang mendukung untuk merepresentasikan suasana kegembiraan Raden Gathutkaca dalam balutan asmara ini, di antaranya: pacak gulu lamba (r), ulap-ulap kedua tangan (r), entrak (r), ulap-ulap kalang-tinantang (r), laku telu pondhongan sampur (r), entrak (r), timbangan (r), tumpangtali (r), tebak bumi kanan-kiri (r), ulap-ulap kirikanan (r), dan pondhongan sampur (r). Ia terkejut setelah sadar bahwa Dewi Pergiwa yang dibayangkan dalam pelukannya ternyata hanya lamunan belaka, ia bergegas mundur dengan melepaskan kedua sampur dan tanjak kanan (r). Ekspresi dari gerakgerak pada bagian kiprahan, iramanya cenderung dinamis dan bernuansa segar, riang, dan gembira.

\section{Alur gerak mundur beksan: adegan semangat (2)}

Bagian mundur beksan merupakan adegan akhir dari seluruh pertunjukan yang menggambarkan semangat dan pantang menyerahnya Raden Gathutkaca untuk meluluhkan hati Dewi Pergiwa. Upaya mewujudkan cita-citanya untuk menggapai cintanya, ia secara bergegas menunjukkan kegagahan, kesigapan, dan semangat maskulinitasnya setelah sadar dari lamunannya. Adapun jenis-jenis gerak yang digunakan untuk mengaktualisasikan rasa semangat Raden Gathutkaca pada bagian ini, di antaranya: tanjak kiri (r), usap brengos kanan (r), usap brengos kiri (r), ukel gelung (r) singsetan sabuk (r), nglurup wangkingan (r), ulap-ulap tawing kiri (r), ulapulap tawing kanan (r), jangkahan kebyokan sampur ke kiri (r), jangkahan kebyokan sampur ke kanan (r), maju ke pojok kiri kebyok 
sampur kiri- tangan kanan menthang miwir sampur trécétan (r), onclang (r), srisik (r), besut (p), jèngkèngan (r), dan berakhir dengan sembahan (r). Ungkapan dari gerak-gerak pada bagian akhir ini cenderung berirama dinamis, tegas, dan bernuansa semangat.

\section{Busana}

Bentuk atau mode busana dalam pertunjukan tari dapat mengarahkan penonton pada pemahaman jenis peran atau figur tokoh. Jenis-jenis simbolis bentuk dan warna busana para penari dimaksudkan mempunyai peranan sebagai: a) identitas peran, b) karakteristik peran, dan c) ekspresi estetis (Maryono, 2012: 61-62). Secara garis besar busana yang dipakai tokoh yang mengidentifikasi Raden Gathutkaca adalah ricikan kotang antrakusuma dengan motif bintang di bagian dada atau tengah dan praba untuk busana badan, sedangkan bagian kepala memakai irah-irahan gelung keling dengan kumis pasangan. Untuk busana kain menggunakan model supit urang.

Warna busana yang dominan tari ini adalah hitam, untuk menggambarkan karakteristik Raden Gathutkaca yang berjiwa tenang, bijaksana, tidak banyak ulah, dan tegas. Merujuk pada cerita bahwa Tari Gathutkaca Gandrung bersumber pada Kitab Mahabaratha, maka selayaknya bila seluruh dandanan bercorak pada wayang.

\section{Rias}

Bentuk rias pada Tari Gathutkaca Gandrung adalah menggunakan rias putra gagah gaya Surakarta. Pola-pola garis sipatan mata dan alis serta godhèk didominasi garis-garis tebal untuk menunjukkan jiwa maskulin yang kuat dan bijak. Untuk memperlihatkan rasa gagah, berwibawa digunakan kumis pasangan yang cukup memberikan kesan keren dan terasa mantap. Kesan gagah Raden Gathutkaca yang berjiwa tegas juga dimunculkan garis-garis sipatan mata yang selain tebal juga terdapat garis-garis yang tegas, sehingga tidak terkesan lemah, diam dan tak bernyali. Kesan secara keseluruhan yang hendak ditampilkan adalah tokoh Gathutkaca tampak gagah, sigrak, maskulin, tegas, kasmaran, dan bersemangat. Sekalipun dirundung rasa asmara terhadap Dewi Pergiwa, kehadiran Raden Gathutkaca tidak tampak murung, namun lebih tampak maskulinitasnya, semangat, dan rasa gembiranya untuk menggapai dan mewujudkan cintanya terhadap sang Dewi. Suasana gandrungan dan rasa gembira Raden Gathutkaca mendominasi seluruh adegan sajiannya yang terpancar dari ekspresi wajahnya.

\section{Musik}

Kehadiran musik dalam pertunjukan tari, rupanya bukan sekadar membantu untuk mewujudkan keinginan tari, namun sebagai bagian yang memiliki kedudukan yang penting dalam mengungkap atau sebagai media ekspresi seniman. Pada awalnya dapat dikatakan bahwa dalam tradisi di Jawa tidak ada repertoar gendhing yang khusus untuk tari, bahkan sebagian besar tarian menggunakan gendhing-gendhing klenèngan yang telah ada sehingga para pendahulu kita menyebutnya gendhing beksan (Rahayu Supanggah, 2009: 149150). Dalam perkembangan selanjutnya musik memiliki peranan penting dalam pertunjukan tari. Humardani mengatakan bahwa dalam tari Jawa, musik karawitan sebagai iringan, banyak membantu mem-berikan kontribusi dan bahkan kerapkali menggantikan kedudukan kekuatan ekspresi tarinya (Humardani, 1991: 10). 
Musik Tari Gathutkaca Gandrung secara keseluruhan terdiri dari beragam jenis gendhing, yaitu: Ada-ada Greget Saut, Sampak, Sendhon Tlutur, Ketawang Kinanthi Pawukir, Ada-ada greget Saut, lancaran Bendrong, Pucung Rubuh, lancaran Bendrong, dan diakhiri dengan Sampak (Slamet Riyadi, 2014: wawancara). Jenis-jenis gendhing yang terdapat pada Tari Gathutkaca Gandrung, secara struktural dapat digambarkan sebagai berikut. Bagian maju beksan, musiknya terdiri dari ada-ada dan sampak. Suasana semangat bagian ini didukung dari rasa ada-ada yang kemudian disambung irama dinamis dari gendhing sampak. Kesan greget, sigrak, semangat yang muncul memberikan aksentuasi pada spirit tampilan jiwa Raden Gathutkaca. Pada adegan sedih ekspresinya didukung musik sendhon yang dilantunkan seorang vokalis putra dengan irama pelan dan memberikan ilustrasi suasana sedih sangat kuat. Kesadaran Raden Gathutkaca berangsurangsur mulai kembali pulih, rasa asmara mulai kambuh, jiwa yang kasmaran mulai semangat dengan tarian asmara yang dibalut dengan musik ketawang Kinanthi Pawukir yang berirama pelan, romantis dengan suasana gandrung yang mantap. Adegan semangat (1) musik sebagai pendukungnya ada-ada. Adegan kasmaran (2) dukungan musik Pucung Rubuh. Adegan gembira yang diaktualisasikan dalam bentuk kiprahan dukungan gendhingnya lancaran Bendrong. Alur gerak mundur beksan pada adegan semangat (2) didukung gendhing sampak yang berirama dinamis dan tegas.

\section{Pemaknaan Tindak Tutur Direktif pada Tari Gathutkaca Gandrung}

Secara kuantitatif pembagian jenis-jenis tindak tutur yang terdapat pada komponen verbal tari ini, jenis tindak tutur yang mendominasi adalah direktif. Capaian secara keseluruhan tindak tutur direktif pada teks Ada-ada Greget Saut pathet sanga, Sendhon Tlutur, Ketawang Kinanthi Pawukir dan Ada-ada Greget Saut pathet manyura, perolehan secara prosentase mencapai: $61.90 \%$. Merujuk pada implikatur masingmasing teks tembang, yang di antaranya: Ada-ada Greget Saut pathet sanga adalah bentuk ungkapan semangat, motivasi dan dukungan terhadap jiwa Raden Gathutkaca dalam menggapai cintanya. Implikatur Sendhon Tlutur yang mengungkapkan kesedihan yang mendalam yang dialami Raden Gathutkaca, ketika mabuk cinta terhadap pujaan hatinya sehingga tidak mampu mengontrol dan jatuh, lemah tak berdaya bagaikan mayat. Implikatur teks Ketawang Kinanthi Pawukir adalah merepresentasikan tentang lamunan rayuannya yang menghendaki agar Dewi Pergiwa tetap menjadi istrinya. Untuk teks Ada-ada Greget Saut pathet manyura implikatur menggambarkan rasa semangat Raden Gathutkaca untuk mewujudkan cintanya terhadap kekasihnya Dewi Pergiwa.

Menurut Leech, bahwa semua implikatur bersifat probabilistik, karena apa yang dimaksud oleh si penutur dengan tuturannya tidak pernah dapat diketahui dengan pasti (1993: 45). Dalam hal ini mitra tutur berupaya merujuk pada kondisi-kondisi yang dapat diamati, bentuk tuturan dan konteks yang kemudian membuat simpulan yang paling mungkin dari seluruh interpretasi evidensi yang ada, sehingga langkahlangkah heuristik dapat menarik makna utama sebagai daya pragmatiknya. Mengacu pada keempat implikatur teks komponen verbal tersebut dapat ditarik maknanya bahwa tari ini menggambarkan perjuangan kehidupan seseorang yang dilanda asmara. Gelora asmara yang tumbuh membara dalam jiwa tidak cukup sebagai bayangan atau 
lamunan, namun perlu mendapat solusi untuk merealisasikan. Dorongan motivasi dan kebulatan tekad rasa cinta Raden Gathutkaca menghantarkannya pada pilihan-pilihan jalan yang menuju kejenjang perkawinan. Sekali pun dengan beragam pergunjingan karena hendak menikahi adik keponakan, maka ia menerima dengan hati yang lapang, mengingat hal itu adalah dampak dari sikap dan tindakan yang telah dipilih sehingga menjadi tanggungjawab sebagai konsekuensi logisnya.

Secara nonverbal tampak bahwa penggambaran figur Gathutkaca yang sedang mengalami kasmaran atau mabuk cinta terhadap Dewi Pergiwa diaktualisasikan dalam bentuk visual tari tunggal yang artistik dengan segala liku-liku permasalahan sehingga kesan kasmaran atau gandrung-nya seorang figur atau tokoh tampak berkualitas mantap. Dukungan yang mampu memberikan kesan Gathutkaca Gandrung, adalah tema, gerak, busana, rias dan musik. Tema yang dipilih adalah percintaan, yang mengangkat cerita Gathutkaca sedang dilanda asmara atau gandrung. Pada tampilan sajiannya tari ini lebih banyak didominasi jenis-jenis gerak yang bersifat representatif yang menggambarkan seorang yang sedang gandrung yang lebih banyak dalam suasana gembira dan semangat, seperti jenis-jenis gerak: podhongan sampur kiri, podhongan sampur kanan, ulap-ulap kedua tangan, entrak, ulaulap kalangtinantang, laku telu pondhongan sampur, timbangan, ulap-ulap kiri-kanan, pondhongan sampur, ogékan lambung dan ogékan lambung gedhegan. Mode busana telah menunjukkan identitas tokoh Raden Gathutkaca dan dukungan rias memberikan kesan karakteristik seorang figur yang gagah, maskulin, tegap, bijak, dan berwibawa. Musikal bernuansa klasik sangat kuat sehingga rasa perpaduan antara gerak-gerak tradisi dan gendhinggendhing Jawa terasa menyatu mantap. Suasana percintaan yang disajikan lebih banyak merepresentasikan rasa-rasa senang, gembira, kasmaran, dan semangat sehingga irama musik yang memberikan dukungan cenderung, dinamis, sigrak, dan romantis. Akumulasi dari beragam unsurunsur: tema, gerak, busana, rias dan musik yang terdapat pada komponen nonverbal telah menunjukkan bahwa secara visual tari ini merupakan karya tari yang berkualitas.

Kehadiran Tari Gathutkaca Gandrung lebih banyak disajikan pada acara-acara resepsi perkawinan yang nota bene wahana untuk mewisuda sepasang pengantin. Pada peristiwa perhelatan resepsi perkawinan dengan disajikannya Tari Gathutkaca Gandrung tampak merupakan sebuah bentuk hiburan dan edukasi yang cukup signifikan terutama terhadap sepasang pengantin dan masyarakat penonton pada umumnya. Kondisi semacam itu sejalan dengan pernyataan, bahwa seni sebagai bentuk ekspresi perasaan manusia merupakan kebutuhan sesuai dengan perkembangan lingkungannya (Mamik Suharti, 2013: 424). Sesungguhnya kesenian pada dasarnya adalah bentuk benda pacu yang apabila dipublikasikan mendapat tanggapan atau penilaian dari publik, sehingga menjadi memiliki arti atau bermakna.

Ekspresi seni bukan ekspresi diri sebab apabila karya seni itu merupakan ekspresi diri semata berarti karya seni mengundang pembaca atau penonton untuk larut dalam kemarahan, untuk itu karya seni justru menjadikan komunikasi itu lebih bermakna, sehingga karya seni bersifat edukatif (Kutha Ratna, 2007: 16). Bentuk edukasi yang dapat dicermati dari peristiwa pertunjukan tari Gathutkaca Gandrung dihadapan sepasang pengantin tersebut, adalah bentuk usaha untuk menyatukan 
rasa cinta yang berkembang menjadi terwujudnya sebuah keluarga yang harmonis membutuhkan sebuah usaha yang keras, semangat, dan pengorbanan yang sangat besar.

Salah satu fungsi bahasa yang berkaitan dengan perintah dinyatakan bahwa fungsi direktif itu lebih berorientasi pada pembaca (Kutha Ratna, 2007: 150). Aplikasinya dalam seni pertunjukan bahwa berkaitan dengan fungsi Tari Gathutkaca Gandrung sebagai salah satu jenis bahasa simbol yang memiliki komponen verbal dengan dominasi tindak tutur direktif, cenderung berorientasi pada penonton (penghayat, penanggap, dan pakar). Dengan demikian makna tindak tutur direktif yang mencapai besaran 61.90 $\%$ pada pertunjukan Tari Gathutkaca Gandrung dalam resepsi perkawinan adat budaya Jawa adalah adanya suatu kehendak yang bersifat perintah dari penanggap yaitu bahwa tari tersebut difungsikan untuk hiburan yang bersifat estetis. Selain itu bagi penanggap kehadiran tari ini merupakan strategi orang tua untuk memberikan pendidikan yang bersifat tidak langsung karena lewat simbol berupa tari yang bertemakan gandrungan. Bentuk perintah yang bersifat tidak langsung yang dibalut dalam bentuk pendidikan adalah perintah untuk mencerap makna yang tersirat pada pertunjukan tari.

\section{SIMPULAN}

Dominasi tindak tutur direktif dalam pertunjukan Tari Gathutkaca Gandrung pada resepsi perkawinan adat budaya Jawa bermakna sebagai bentuk perintah bersifat tidak langsung yang dibalut dalam penyajian estetis dan memiliki nilai pendidikan. Kehendak orang tua atau sebagai penanggap menghadirkan Tari Gathutkaca Gandrung adalah untuk memberikan hiburan yang bersifat estetis terhadap sepasang pengantin khususnya dan penonton pada umumnya. Karya seni adalah sarana kehidupan estetis, yang sengaja dicipta, dikontrol, dan dikomunikasikan oleh seniman sebagai aktualisasi ekspresi, sehingga tidak ada hal-hal yang tidak berarti, tidak relevan atau mengganggu (Parker, 1980: 36-42). Pada dasarnya karya seni itu memberikan kenikmatan indera yang pada tahap selanjutnya memberi kepuasan jasmani dan rohani secara menyeluruh. Kenikmatan olah estetis pada prinsipnya merupakan olah rasa pada manusia sehingga jiwanya menjadi lebih halus, lebih santun, tenggang rasa semakin meningkat, lebih peka terhadap kondisi lingkungan sehingga jiwa kemanusiaannya berkembang supaya sikap, perilaku, dan tindakannya menjadi lebih baik, berakhlak dan berkeadaban.

Makna direktif ini merupakan harapan orang tua yang menghendaki sepasang pengantin sebagai anaknya supaya dapat menyerap makna yang terkandung dari penyajian Tari Gathutkaca Gandrung dan mencotoh sebagai bekal untuk membina rumahtangga yang harmonis dan bahagia. Adapun makna pendidikan yang diharapkan dapat diserap bagi sepasang pengantin bahwa untuk menyatukan rasa cinta yang berkembang menjadi terwujudnya sebuah keluarga yang harmonis membutuhkan sebuah usaha yang keras, semangat, dan perjuangan yang besar secara fisik dan nonfisik. Untuk itu bentuk usaha dan kerja keras yang telah dilalui oleh sepasang pengantin untuk diupayakan selalu dijaga, dilestarikan, dan dikembangkan menjadi prinsip dasar untuk membina keluarga yang harmonis dan bahagia.

\section{Catatan Akhir}

Ada-ada adalah lagu solo vokal yang dipadukan dengan instrumen gender dan dhodhogan ataupun keprak, sendhon merupakan 
garap tembang jawa yang bernuansa sedih, gerongan adalah lagu vokal bersama yang lagunya dipacu irama ketukan nada.

\section{Daftar Pustaka}

Asim Gunarwan.

2005 "Pengutamaan Pragmatik". Makalah Seminar Nasional. Surakarta: PPS S3 Linguistik UNS.

Gie, The Liang.

1976 Garis Besar Estetik (Filsafat Keindahan). Yogyakarta: Karya.

Humardani, SD.

1991 Pemikiran \& Kritiknya. Editor: Rustopo. Surakarta: STSI Press.

Koentjaraningrat.

1972 Beberapa Pokok Antropologi Sosial. Jakarta: PT Dian Rakyat.

Kutha Ratna.

2007 Estetika Sastra dan Budaya. Pustaka Pelajar. Yogyakarta

Levinson, Stephen C.

1983 Pragmatics. London: Cambridge University Press.

Leech, Geoffrey.

1993 Prinsip-prinsip Pragmatik. Penerjemah: M.D.D Oka. Jakarta: Universitas Indonesia.

Lamuddin Finoza.

2005 Komposisi Bahasa Indonesia. Jakarta: Diksi Insan Mulia.

Maryono.

2010 Pragmatik Genre Tari Pasihan Gaya Surakarta. Surakarta: ISI Press.

2012 Analisa Tari. Surakarta: ISI Press.

Mamik Suharti.

2013 "Tari Ritual dan Kekuatan Adikodrati". Jurnal Panggung, Vol. 23 No. 4 Desember. STSI Bandung.

Mey, J.L.

1998 "Pragmatic". dalam Mey, J.L dan R.E. Asher (Eds) Concise Encyclopedia of Pragmatics. Amsterdam: Elsevier.
2001 Pragmatics: An Introduction, second editional. Oxsford: Blackwell.

Nanik Sri Prihatini Dkk.

2007 Ilmu Tari: Joget Tradisi Gaya Kasunanan Surakarta. Surakarta: Pengembangan Ilmu Budaya bekerjasama dengan ISI Press Surakarta.

Parker, De Witt.H.

1980 Dasar-dasar Estetika. Terjemahan:SD. Humardani. Diterbitkan: Akademi Seni Karawitan Indonesia (ASKI) Surakarta.

Parker, Frank.

1986 Linguistics for Non-linguists. London: Taylor and Francis Ltd.

Rahayu Supanggah.

2009 Bothekan Karawitan II: Garap. Surakarta: Program Pascasarjana bekerja sama ISI Press Surakarta.

Silvester Pamardi.

2000 "Peranan S. Maridi Dalam Perkembangan Tari Gaya Surakarta (Sebuah Biografi)". Tesis. UGM Yogyakarta.

Weiner, Myron.

1986 Modernisasi Dinamika Pertumbuhan. Yogyakarta: Gadjah Mada University Press.

Yule, George.

2006 "Pragmatik" terjemahan dari Pragmatic oleh Indah Fajar Wahyuni. Penerbit: Pustaka Pelajar Yogyakarta.

\section{Nara Sumber}

1. Sutarno Haryono. 56 tahun.

Dosen Tari ISI Surakarta, Penari Putra Gagah, dan Sutradara Seni Pertunjukan.

2. Suyanto (53 th).

Dosen Pedalangan ISI Surakarta dan Seorang dalang Gaya Jawa Timuran.

3. Slamet Riyadi, (54) tahun.

Dosen Karawitan ISI Surakarta dan Seorang Pengrawit dengan spesialis instrumen gendèr. 